\title{
Montaña y despoblación. Un decálogo de medidas para mantener ocupado dinámicamente el territorio de montaña ibérico
}

\section{RESUMEN}

Se trata de evaluar el concepto geográfico de montaña en España y Portugal, concretándolo en una región paradigma, Asturias. Se analiza la fuerza de la tendencia que conmueve el territorio de montaña, el despoblamiento, y se definen las características de su evolución, relacionándola con las políticas públicas que se aplican en ellas. La demografía recompone buena parte del territorio de montaña y pone en cuestión su naturaleza al despoblarlo. Para frenar esta tendencia se plantea un decálogo de medidas que aspiran a componer un modelo de gestión territorial, enfocado al mantenimiento de la ocupación dinámica del territorio, mediante la ampliación de capacidades locales y la economía de la identidad.

\section{RÉSUMÉ}

Montagne et dépeuplement. Un décalogue de mesures visant à maintenir le territoire des montagnes ibériques occupé dynamiquement.On évalue ici le concept géographique de montagne en Espagne et au Portugal, centré sur une région paradigme, les Asturies. La force de la tendance qui se déplace sur le territoire de montagne, le dépeuplement, est analysé, et les caractéristiques de son évolution sont définis, et ils sont en relation avec les politiques publiques qui leur sont applicables. La démographie recomposés grande partie du territoire de montagne et remet en question sa nature. Pour freiner cette tendance l'article propose un décalogue de mesures qui visent à composer un modèle de ges-

\section{INTRODUCCIÓN}

$E^{n}$ n 1974 la Universidad de Valladolid editaba la tesis doctoral del profesor Ortega Valcárcel (1974), dedicada a las montañas de Burgos. Dos años después el CSIC publicaba la del doctor Daumas (1976), sobre el alto Aragón oriental. En 1980 el Instituto de Estudios tion territoriale, axée sur le maintien de l'occupation dynamique du territoire en augmentant les capacités locales et la economie de l'identité.

\section{AbSTRACT}

Mountain and depopulation. A Decalogue of measures to maintain dynamically occupied territory of Iberian mountain.- This article is about assessment of the geographical concept of mountain in Spain and Portugal, focused in a paradigm-region, Asturias. The strength of the trends that moves at the mountain territory it is analyzed and the characteristics of their territorial evolution is defined, relating to public policies that are applied to them. Demographics reconstructs the territory and puts in question their nature to depopulate. To curb this trend a decalogue of measures that aim to compose a territorial management model, focused on maintaining the dynamic occupation of the territory by expanding local capacity and the economy of identity.

\section{Palabras clave/Mots clé/Keywords}

Montaña, despoblación, economía de la identidad, sistema territorial, lógica de proyecto, enfoque de las capacidades, ocupación dinámica del territorio.

Montagne, dépeuplement, économie de l'identité, logique de projet, approche des capacités, occupation dynamique du territoire.

Mountain, depopulation, identity economy, territorial system, logic of the project, capabilities approach, the dynamic occupation of the territory.

Pirenaicos editó una monografía dedicada a dar orientaciones para la promoción de la vida rural en la montaña española (Anglada y otros,1980). Preámbulo, conclusiones y algunos capítulos interiores fueron obra de quien llevaba mucho años como su director, el doctor don Enrique Balcells Rocamora. Un cuarto de siglo después, uno de sus discípulos y coautor de dicho libro, J. 
M. García Ruiz (2006), decía que «aún le sorprendía por la frescura de algunas ideas que no hemos sido capaces de explotar en su totalidad». Esto también puede decirse de las dos monumentales obras anteriores, aunque hay otras de carácter geográfico igualmente significativas en esa década. Ellas extendieron la preocupación positiva sobre el estado de las montañas españolas y, así, la Constitución española, en su artículo 130.2, reconoce el carácter especial de los territorios de montaña y reclama de los poderes públicos que lo traten como tal. Lo que hicieron a través de la ley 25/ 1982 de Agricultura de Montaña, que recogía algunas ideas explicitadas en el libro de Anglada y otros (1980, pp. 95-96); entre otras, asignaba como misión a la montaña la de ser reserva energética. Idea muy querida al doctor Balcells y que es la base del programa Evaluación de los Ecosistemas del Milenio (MEA, 2010), que estudia los servicios que ofrecen los ecosistemas del planeta a la vida social y al bienestar de los humanos. El hombre humanizó con intensidad la montaña y hoy autores como Aguiar y otros (2009) y Fillat y otros (2010) tratan de identificar y precisar la aportación que prestan las montañas a la dotación de servicios y justificar en el presente su condición de patrimonio valioso para la especie.

Aun así, la supervivencia de la montaña como territorio pasa por encontrar actividad industriosa para ella. En el pasado ésta se había conseguido a través de un proceso cultural, que había depurado unos sistemas de gestión territorial, de equilibrios delicados, dinámica lenta y fragilidad ante las pulsiones externas y bruscas, que los perturban hasta llevarlos a la despoblación y a la desactivación productiva. Ambos procesos (crisis demográfica y productiva) se enlazaron en las últimas décadas en España en un círculo vicioso que condujo a la desvitalización de sus montañas, a la fragmentación del territorio, a la descohesión del país y amenaza la continuidad en la prestación de estos servicios o misión general de la montaña.

El estadio en el que nuestra civilización se encuentra, caracterizado por la urbanización, lleva a la polarización en las ciudades, que se agrandan, y da regiones estrictamente jerarquizadas, en las que si sus espacios rurales se despueblan, el proceso aún adquiere mayor importancia en las montañas, lo que hace que esta característica regional se sienta como un problema «grave» o «muy grave» por la ciudadanía (Gómez Limón y otros, 2007, p. 50) y por las instituciones, como el Senado (2014), que crea la «Comisión Especial para el estudio de medidas a tomar para evitar el despoblamiento de las zonas de montaña». En esta perspectiva crítica, por proponer alternativas úti- les para encarar problemas del tiempo actual, se encuadra este artículo, que enlaza con otros dos anteriores para dar continuidad a una serie personal (Rodríguez Gutiérrez, 1987 y 1993), que concluye con un decálogo de medidas para integrar un modelo de asentamiento de la población en los territorios de montaña españoles, basado en el enfoque de las capacidades territoriales y en la lógica de proyecto territorial (Rodríguez Gutiérrez, 2004, pp. 107115). Esta intención práctica tiene muy presente que la montaña induce diversidad y que son las diferentes circunstancias, que organizan o desorganizan los territorios, las que incrementan los rasgos diferenciales hasta alterar gravemente la cohesión del territorio. Se trata de contribuir a trabar un modelo de gobernanza capaz de orientar la intervención en algunos territorios de montaña, en los cuales es necesario mantener una base demográfica que asegure su ocupación dinámica mediante un modelo multifuncional.

Si la montaña genera diversidad, no se puede hablar de una montaña ocupada en exclusiva por una sociedad agraria o incluso rural. Hay diferentes tipos de territorios de montaña, pero todos definidos por unas condiciones generales: elevación y pendiente, que inducen fragilidad (facilidad para romper los equilibrios internos del territorio) por su vulnerabilidad (debida a la alta exposición a la acción de la gravedad), ya sean montañas de ocupación metropolitana, urbana, rural o de clímax natural. Cuando el sistema territorial montañoso no sabe o no puede defenderse, la vulnerabilidad se convierte en fragilidad. De ahí que el sistema agrario tradicional estuviera diseñado para atenuar la acción de la gravedad, limitando la tendencia natural de los componentes del sistema a seguir la dirección de la pendiente, nutriendo así a otros situados más abajo. Por eso Balcells (1978) hablaba de la montaña como reserva.

Reserva de importantes recursos para la sostenibilidad de los sistemas territoriales que están aguas abajo y valiosa en sí misma como plataforma de actividad adaptada a sus capacidades y a su misión geográfica general. La montaña, como otros territorios rurales, ha acogido en el pasado a un sistema agrario tradicional que, en general, no ha podido evolucionar hacia otros tipos de agricultura o ganadería o ha conocido focos de actividad polarizados vinculados a nuevas actividades. Una y otra no han sido suficientes para integrar el territorio de montaña en el sistema general. Aquí se hace una reflexión sobre los territorios de montaña peninsulares, españoles y portugueses, y se cualifica su población y poblamiento, concretando los procesos de ambas dimensiones territoriales en la región paradigma Asturias. 


\section{LA DIMENSIÓN DEL ÁREA DE ESTUDIO EN ESPAÑA Y PORTUGAL}

Definimos la montaña como el producto geográfico de la convexidad y rugosidad de una cierta parte de la superficie del planeta. Ambos factores determinan procesos ecológicos y la configuración paisajística. El sintagma espacio de montaña lo hacemos equivalente al de zona de montaña; ésta debe contener varias fajas bioclimáticas determinadas por la altura, y es una clasificación administrativa del territorio, para aplicar políticas públicas específicas destinadas a tratar problemas comunes en ellas.

Territorio de montaña es el que mantiene las condiciones físicas propias de la montaña en un espacio superficialmente extenso, que hacen que se module la utilización del mismo por una comunidad que lo gobierna en función del ciclo solar, cuyos elementos participantes dan forma a un sistema territorial que se ocupa de la gestión hombre-recurso, utilizando sus capacidades para garantizar su función de reserva energética. El sintagma sería equivalente a país montañoso.

El sintagma región de montaña lo utilizamos para referirnos a ciertas regiones políticas con la mayor parte de su territorio clasificado como zona de montaña. Igualmente, utilizamos el concepto de región montañosa para referirnos a un trozo de la superficie terrestre amplio, extenso y contrastado que puede abarcar varios países de comunidades autónomas y que incluye zonas de montaña y otros municipios contiguos que pueden no serlo.

En España, la ley de Agricultura De montaña ha precisado los criterios para delimitar la zona de agricultura de montaña (ZAM), tomando como unidad el municipio, cuya lista se ha confeccionado a propuesta de las comunidades autónomas, entre los que cumplen las condiciones impuestas por la ley $25 / 1982$ y las directivas $86 / 466 /$ CEE y 91/465/CEE, dictadas con arreglo a la directiva 75/268/CEe. Sucesivas órdenes ministeriales de 1985, 1986 y 1987 fueron estableciendo la lista de municipios incluidos dentro de las zAM. Posteriormente se le añadieron modificaciones, derivadas de la salida de municipios, por desaparición, o de la entrada de otros, a propuesta de los Gobiernos regionales, aprobadas por los respectivos comités de seguimiento de los programas de desarrollo rural. Recientemente el reglamento UE-1305/2013 estableció el régimen de ayudas al desarrollo rural en las zonas con limitaciones naturales, como las de montaña.

El espacio clasificado como zona de agricultura de montaña en España ocupa el $42 \%$ del territorio nacional, $212.352 \mathrm{~km}^{2}$ (Fernández Arroyo, 2003, p. 46, y Atecma, 2006, p. 152), lo que convierte a España en el segundo
Estado legalmente más montañoso de Europa, tras Suiza, cuya ley de Montaña (LiM) de 1974, renovada en 1977, no establece unos criterios y a su tenor una lista de comunas de montaña, sino que identifica las zonas de montaña como grupos de municipios que forman un conjunto geográfico y tienen como objetivo la resolución conjunta de problemas comunes. Estos conjuntos municipales se forman voluntariamente y además de trabajar en cooperación para enfrentar retos, también tienen en cuenta rasgos de identidad cultural y evolución geográfica compartida, especialmente referida a su dinámica demográfica a largo plazo, a su capacidad económica y a las dotaciones públicas. Esta es una vía interesante para aquellas comunidades autónomas plenamente de montaña y en las que las variantes internas deben establecerse por otras peculiaridades distintas a las físicas. Para Asturias fue la que se empleó para el estudio de la diversidad de su montaña legal (Rodríguez Gutiérrez, 1987) con el resultado de aislar unidades territoriales de características y evolución homogéneas, lo que permitía establecer una lógica de proyecto más territorial que local; la que el tiempo y los nuevos criterios de las políticas europeas de cohesión y de desarrollo rural reclaman; además de la ley 45/2007 para el Desarrollo Sostenible del Medio Rural o «espacio geográfico definido por las administraciones competentes que presenta una población inferior a 30.000 habitantes y densidad inferior a 100 habs. $/ \mathrm{km}^{2} »$, dentro del cual se diluye la especificidad de la problemática montana, lo que hace a algunos plantearse la conveniencia de una ley general para la montaña española.

Pero si la zona de montana es una clasificación administrativa que permite trazar su perímetro con facilidad, delimitar la montaña es más difícil, pues no hay unanimidad en la elección de los criterios a utilizar, ya que sólo están libres de controversia la altitud y la pendiente. Atecma (2006, p. 138), aplicando a España un modelo general empleado para delimitar la montaña europea y utilizando dos variantes, encuentra un par de resultados para definir perimetralmente el espacio que ocupa la montaña en España. Así, según el modelo 1, la montaña peninsular más la balear sumaría el $54 \%$ de la superficie española, lo que encuentra excesivo; aplicando el modelo 2, la superficie de montaña se reduciría al $39 \%$. El listado de municipios clasificados administrativamente como zona de montaña, 3.029 (Atecma, 2006, p. 152), viene a aproximarse al modelo 2 , que incluye 2.945; si bien hay discordancias, pues unas comunidades autónomas han sido más restrictivas al clasificar, como Aragón, Cataluña y Andalucía, y otras más generosas, como Castilla-La Mancha y Castilla y León. 




FIg. 1. Zonas desfavorecidas de montaña en España y Portugal.

En una perspectiva peninsular la dimensión del espacio clasificado como desfavorecido de montaña en el Portugal continental significa un porcentaje algo inferior. Si consideramos como montaña la superficie situada por encima de los $700 \mathrm{~m} / \mathrm{a}$., resulta el $11 \%$ de la superficie total portuguesa, unos $10.000 \mathrm{~km}^{2}$ (Aguiar, 2009), concentrada en la mitad norte del país (sierras Galaico-Portuguesas, sierras Galaico-Durienses, sierras Beira-Durienses, Sistema Central y sierras de San Mamede y Monchique). Si consideramos todos los criterios de delimitación utilizados por la Administración portuguesa, la cifra de superficie clasificada como zona de montaña estaría alrededor del tercio de la nacional (Cortés, 1995, p. 57). Los criterios de clasificación son los que establece la CEE a partir de la directiva 75/268/CEE, si bien el umbral de altitud que la Administración portuguesa utiliza es el de 700 m/a. media en el concejo, mientras que la española utiliza el de 1.000 m/a. s. n. m. en el $80 \%$ del término municipal. La pendiente umbral es del $25 \%$ de media en la superficie del municipio para Portugal y del $20 \%$ para España. El desnivel también cualifica, a partir de 400 m en Portugal y de $600 \mathrm{~m}$ en España. Cuando no se alcanzan los valores de desnivel o pendiente antedichos, pero se dan en un cierta medida, su acción combinada habilita para clasificar municipios de más de 400 m en Portugal y 600 m/a. en España y pendiente media superior al $15 \%$ en ambos países.

La dimensión superficial de la zona de montaña en los dos países ibéricos horquilla por tanto el valor medio para la Unión Europea de los 28 miembros, en la que representa aproximadamente el $30 \%$ de su superficie en la que reside el $17 \%$ de la población (ENRD, 2013).

\section{LA IMPORTANCIA REGIONAL DE LAS MONTAÑAS IBÉRICAS}

La comunidad autónoma más montañosa es el Principado de Asturias, con un $94 \%$ de su territorio clasificado, seguida a poca distancia por Cantabria, en la que el territorio ZAM alcanza, después de la última ampliación de 2013, el 90 \% de la superficie regional, y, en tercer lugar, el País Vasco, con 190 de sus 250 municipios, el $85 \%$ de su superficie, delimitados como ZAM. Galdós y Ruiz (2008) argumentan sus razones para reducir a 152 los municipios vascos incluidos, lo que representaría el $64 \%$ de la superficie vascongada, en la que reside el $13 \%$ de su población. Aun con esta reducción, ambos autores (2008, p. 37) insisten en la heterogeneidad del territorio delimitado, lo que les da pie para crear una tipología de municipios de montaña en el País Vasco. Estas tres comunidades autónomas y otras siete más (Canarias, La Rioja, Navarra, Galicia, Andalucía, Cataluña y Castilla y León) presentan alrededor de la mitad de su territorio regional clasificado como zona de montaña, siendo la que menos Extremadura, con cerca del $15 \%$.

En Portugal la zona de montaña se extiende en la vecindad del nodo ibérico de la Gran Cantábrica, en las regiones de Trás-os-Montes, donde llega a significar el $40 \%$ de su superficie (Aguiar y otros, 2009, p. 298) y en la Beira Alta (sierras de Montemouro, Freita, Leomil, Lapa y Penedono); en la Beira Baixa la espina central hispánica está representada por las sierras de Malcata, Estrela (Torre 1.993 m/a.), Gardunha, Açor e Lousã, ocupando en ambas Beiras el espacio clasificado de montaña algo más de un cuarto del total. Estas son las terras frias, que ofrecen un gran contraste en su ocupación con el cordón litoral. En la región miñota, que contiene las sierras de Arga y de Corno do Bico, la montaña es significativa y mucho menos en el alto Alentejo, con el pequeño enclave de San Mamede, y en Algarve, con la sierra de Monchiqe. Las islas básicamente son montaña, en las que los caracteres propios de la montaña se entrecruzan con los de la insularidad periférica.

En Cataluña el territorio clasificado de montaña ocupa la mitad de su superficie y en él reside sólo un $5 \%$ de la población. Aragón, con más o menos la misma proporción de superficie clasificada, registra más de la mitad de su población en la comarca de Zaragoza, mientras que otras cuatro (Maestrazgo, Albarracín, Gúdar-Javalambre y Sobrarbe) presentan densidades inferiores a 3 habs./ $\mathrm{km}^{2}$. En la ZAM cántabra reside el $35 \%$ de la población regional. En Asturias, en cambio, en su zona desfavore- 


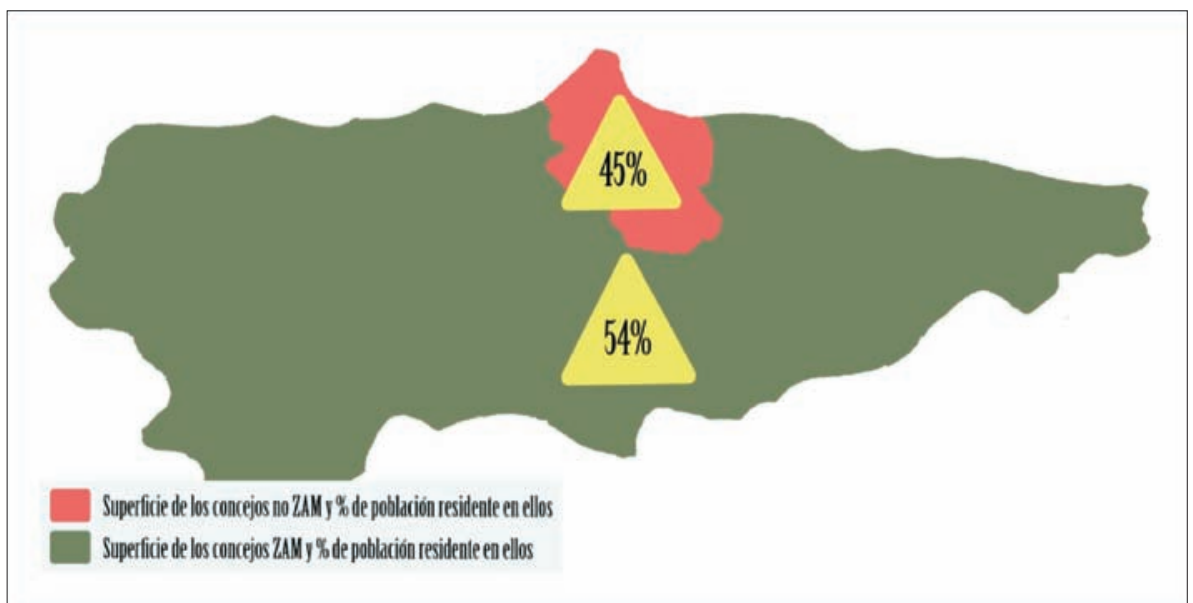

FIG. 2. Distribución de la población en Asturias según resida en concejos clasificados como ZAM o no ZAM en 2013. cida de agricultura de montaña vive algo más de la mitad (54\%) de sus habitantes; el exiguo espacio restante, que no es ZAM (6\%), se presenta como enclave costero central, distribuido en nueve concejos que concentran casi la mitad de la población. Si a este enclave de territorio no clasificado como ZAM le añadimos el municipio contiguo y capital, Oviedo, que por fidelidad a la identidad del país no podía ser sino montañés, creamos una de las áreas metropolitanas mayores de España y de la fachada atlántica europea, donde residen, sobre algo menos del $10 \%$ de la superficie regional, los dos tercios de su población, esto es, 719.537 habitantes, por lo que el $90 \%$ restante, que si está clasificado como ZAM está habitado por 357.537 residentes en 2013. Un aparte de los cuales vive en municipios claramente urbanos (con más de 100 habs./ $/ \mathrm{km}^{2}$ ) contiguos y clasificados como ZAM. Así, el país se halla completamente basculado hacia su área central, que geográficamente es metropolitana, montañosa y costera, y que concentra, en el $14 \%$ del territorio regional, al $80 \%$ de los residentes en Asturias.

Por tanto, tenemos que concluir que toda Asturias es montaña, que la identidad del país viene determinada por su geografía montañosa y que, por ello, es un perfecto laboratorio para ilustrar fenómenos generales relacionados con la montaña, de la que Asturias es una región paradigma.

\section{ELEMENTOS PARA UNA DISCUSIÓN SOBRE LAS CARACTERÍSTICAS GENERALES DE LAS MONTAÑAS IBÉRICAS}

La montaña está determinada por características físicas como la altitud, la pendiente, la extensión superficial y la latitud, del resultado de cuyo manejo surgen situaciones diversas. La altitud es un marcador significativo y correlaciona estrechamente con el termoclina, por lo que al resultar fácilmente cartografiable es el de referencia. Pero no sólo estos rasgos definen su estado; como sistemas territoriales están incluidos en otros, que los contienen y también determinan. Vistas a escala europea, las regiones montañosas mantienen comportamientos similares según se encuentren en los distintos ejes de desarro1lo. A primera vista parece que los rasgos generales de la montaña a escala suprarregional se matizan con la pertenencia a ejes de desarrollo centrales o periféricos, manifestándose diferencias sensibles si están incluidas en regiones motoras o en espacios de integración. Así en CPRM/ AAC (2005) Asturias se encuentra fuera de los llamados «espacios motores», compartiendo su territorio dos tipos de espacios de integración, el de fuerte potencial (centro y área costera) y el débil potencial (interior montañoso) en el que el despoblamiento es un problema general, pero no común a todas las zonas de montaña, pues, como más adelante veremos, en el espacio clasificado de montaña en Asturias, que además es costero, reside casi la mitad de la población regional, mientras que en el interior no metropolitano apenas reside un décimo del total, lo que constituye una amenaza para su consideración como territorio de montaña, pues de proseguir el despoblamiento pasará a ser simplemente espacio al vaciarlos de ocupación humana. No obstante, hay que tener en cuenta que la gradación de ambientes que introduce la altura hace que ciertas partes del territorio sólo sean aprovechables en ciertas épocas del año o desde cierta distancia, por lo que las densidades están relacionadas con el sistema de gestión territorial, y en el caso de Asturias desde mitad del siglo xx estuvo orientado a la explotación semiexten- 


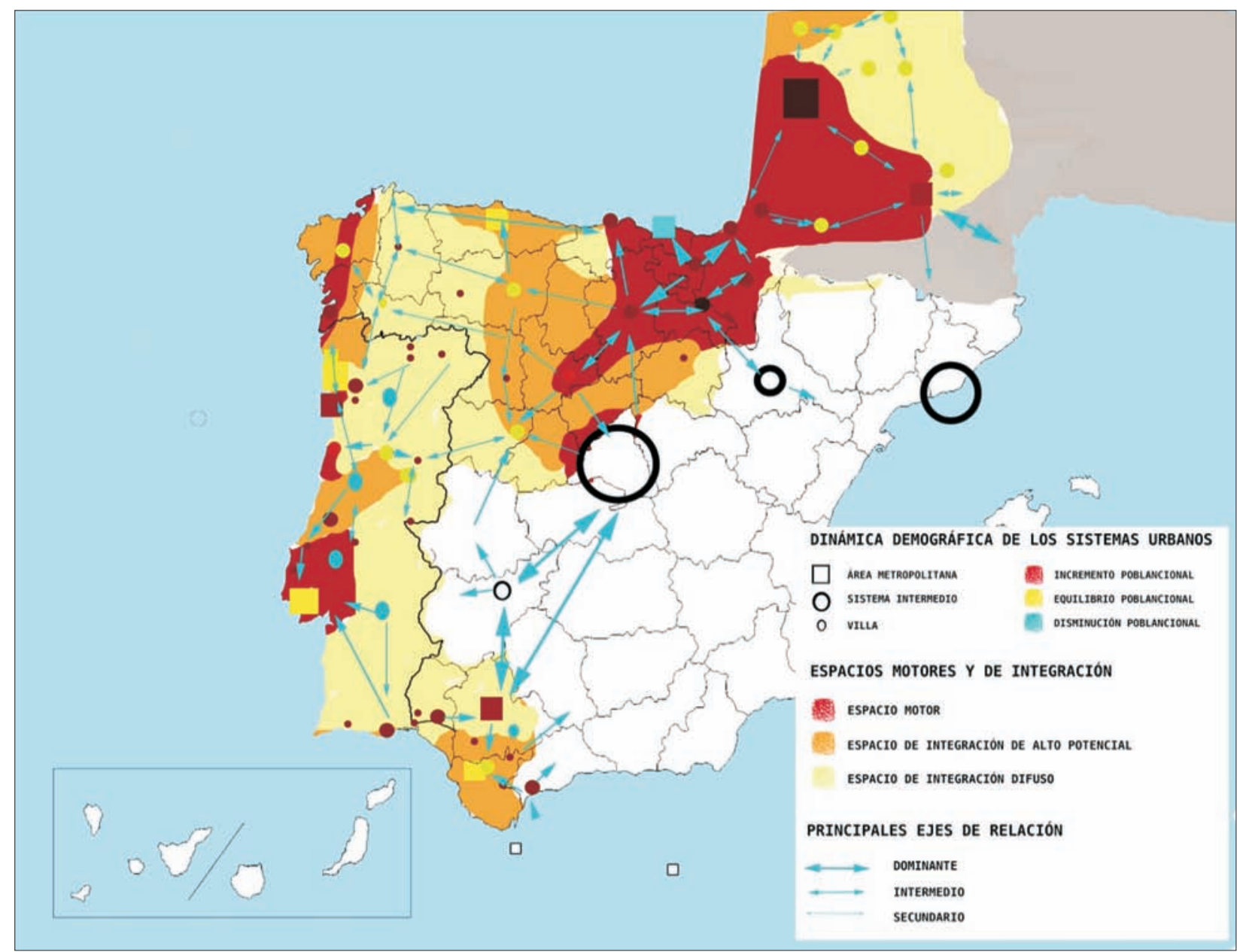

FIG. 3. Espacios motores de desarrollo y de integración en la fachada atlántica española. Asturias en la región rayana meridiana.

siva de vacuno, lo que no exige una alta densidad para el mantenimiento de tal sistema agrario.

El enclavamiento es una característica de las montañas, pues cuesta llegar al lugar. Aún dentro de los ejes motores de desarrollo, las montañas presentan la fricción de la rugosidad ya que no de la distancia. Como característica general de los territorios de montaña el enclavamiento es también un rasgo de la región paradigma, Asturias, lo que confirma de nuevo Atecma (2006) cuando analiza este rasgo en las montañas de España y hace coincidir ejes montañosos con ejes de baja accesibilidad. Según esto, la Península estaría integrada por tres bandas oblicuas y paralelas (NE-SO) de baja accesibilidad, entre las que se intercalan otras de alta accesibilidad. Las primeras son el eje Jaca-Tortosa o Pirineos-Maestrazgo; la segunda, el eje Ribadedeva-cabo de Palos o Picos de Europa-Sistema Ibérico sub-bético, y la tercera, la Gran
Cantábrica-Sierra Morena. Por tanto, dos de las tres arrancan en Asturias.

Aunque se asocia el término «la Montaña»a Cantabria, efectivamente la Asturias de Santillana era la Montaña, sí, pero de Castilla. La Asturias de Oviedo era la de León, aún más abrupta y más desconocida por enclavada, pues no estaba enganchada a la línea axial castellana (Madrid-Valladolid-Santander), ya que hacía de nodo elevado y original de la raya fronteriza y marginal ibérica. Y aún continúa siendo igual, como se demuestra en la Fig. 4, donde la raya adquiere grosor para constituir una región fronteriza, montañosa las más de las veces y casi vacía siempre, que desde las marinas asturgalaicas sigue la meridiana hacia el sur y asciende al nodo de la Gran Cantábrica, compartido por las montañas orensanas, asturianas, leonesas, zamoranas y trasmontanas. Macizo enclavado y abigarrado en cuyo corazón an- 
fructuoso se encuentra el inaccesible Valledor, el valle de oro, estrecho y enclavado, adecuado para guardar el tesoro de la más profunda ruralidad. La que custodia Finisterre, en las montañas del noroeste ibérico, intercaladas entre el espacio motor, el que irradia la bisagra vasca y el que rebosa Madrid, y el eje litoral luso-galaico. En el medio aparece esta lengua montañosa de disposición meridiana, con una curiosa cabecera metropolitana, Ciudad Astur, un corazón de tradición rural, y un core de larga civilización ibérica. Pero el concepto «enclavado», aunque parte de la realidad física propia de la montaña, tan determinante durante la historia de la humanidad, incluye una dimensión dinámica, pues tiene la acepción de «pasar, atravesar»; por tanto, la condición de enclavada, aunque general, no es inmanente a la montaña; ésta no está condenada por un fatal destino, se puede desenclavar, por lo que éste es un objetivo pertinente de su proyecto de desarrollo.

La fragmentación del territorio es otra característica que inducen las montañas, tanto en la gran escala, en su interior, por la presencia de concavidades y convexidades que las arrugan, como a pequeña escala cuando se visualizan como componentes de las regiones o de los grandes países. La fragmentación no se debe tanto a la presencia de formas de vida o sistemas productivos diferentes, pues tradicionalmente eran distintas las economías y los asentamientos de la montaña y del llano o de la ciudad, pero antes estaban enlazados complementariamente en sistemas menos polarizados. La fragmentación hoy se debe a la presencia de sistemas territoriales con dinámicas muy contrastadas, de líneas tendenciales divergentes, que apuntan a futuros opuestos. Unas y otras operan sobre sistemas más o menos estancos, no integrados regionalmente, por lo que el asunto afecta a la cohesión en las distintas escalas. Siendo el principio de la cohesión territorial una de las piezas clave de la construcción europea, las montañas se convierten en un territorio donde poner a prueba las políticas específicas derivadas de este principio, y no sólo las agrarias, ambientales o de desarrollo rural de las zonas desfavorecidas.

La tendencia sistémica a la polarización parece que se acentúa en la montaña, dando lugar a contrastes entre territorios muy próximos. Lo vemos en Ciudad Astur, el artefacto metropolitano cuya naturaleza montañosa la convierte en una «ciudad digital»; pues, en una buena parte, se extiende siguiendo los fondos de valle, dejando vacías las laderas intermedias, y no se disemina al modo tradicional con coronas concéntricas. Y lo vemos también en el interior montañoso del país, pues la sensación de vacío aún es mayor de lo que indican las cifras, ya que las vi- llas concentran la escasa población de los municipios y permiten mantener la ocupación del territorio, siendo los últimos bastiones de ciudadanía frente a la naturalización del resto. Para calibrar estos procesos a veces la escala municipal es demasiado gruesa, necesitando de escalas mayores para percibir el detalle de las sensibles diferencias territoriales, para eso sirve la parroquia, que sigue siendo un buen instrumento para hilar fino en la montaña, ya sea metropolitana o rural.

Delgado y Plaza (2012, p. 10) establecen un modelo de clasificación del territorio de montaña español en el que descubren un «mosaico muy dispar de estructuras y modelos espaciales» que clasifican en tres conjuntos: «espacios en regresión y con pervivencia de rasgos tradicionales, espacios en proceso incipiente de rehabilitación y espacios con fuerte impacto/presencia de los procesos de urbanización». En todo caso, el asunto de la clasificación de las áreas de montaña en España «queda pendiente de un proceso conjunto de reflexión» al que llamaba la Carta Española de las Montañas (Magrama, 2005), que veía «necesario determinar y aprobar una definición común para las regiones de montaña, adaptada a las características de nuestro país, con independencia de las definiciones dirigidas a regular la indemnización compensatoria en el sector agrario». El documento de 2011, correspondiente al texto de dicha Carta aprobado por el grupo de trabajo de la Red Rural Nacional, parece considerar que el proceso de reflexión conjunta ya se ha dado, cristalizando a estos efectos en la ley 42 /2007 del Patrimonio Natural y de la Biodiversidad, que considera como áreas de montaña aquellos «territorios continuos y extensos, con altimetría elevada y sostenida respecto a los territorios circundantes, cuyos rasgos físicos causan la aparición de gradientes ecológicos, que condicionan las organización de los ecosistemas y afectan a los servicios y a las sociedad humanas que en ellos se desarrollan».

La definición puede que le hubiera gustado al doctor Balcells; puede también que echara en falta una referencia al papel de la montaña como reserva sistémica. El método de delimitación, «los procesos de selección y determinación concreta» de las áreas de montaña, parece combinar también la idea de proyecto de desarrollo territorial, en el sentido de la clasificación utilizada en Suiza, que aquí se deja a «las administraciones autonómicas y locales (las cuales) establecerán procesos de consulta y consenso».

En resumen, la heterogeneidad de situaciones es un rasgo de la familia territorial de la montaña, que si bien está determinada en primera instancia por su naturaleza 
física, el gran juego territorial en sus diferentes escalas va incorporándoles a nuevos conjuntos y dándoles nuevas experiencias que se resuelven de distintas maneras, también contingentes, y que acentúan la natural diversidad que de partida introducen los rasgos físicos. No obstante, siendo la población estructurada el elemento determinante en el concepto territorio, sus características demográficas son crisol de dinámicas y rasgo significativo para caracterizarla. En casi todos los tipos de montaña, aunque no en la generalidad, aparece la tendencia demográfica como un problema, por su fuerte carácter perturbador del sistema territorial. Exponemos a continuación los grandes rasgos del fenómeno en la región paradigma, comenzando por revisar la evolución reciente.

\section{LA SEGUNDA TRANSICIÓN DEMOGRÁFICA EN LAS MONTAÑAS IBÉRICAS}

En Asturias, a finales de la década de 1970 no podría decirse que el despoblamiento fuera su característica más relevante. El país había conocido desde comienzos del siglo pasado diferentes procesos de modernización; a finales de la segunda década del siglo xx puede decirse que ya estaba concluida la transición demográfica. El potencial ganadero era dominante y constituía la especialización agraria. La plenitud del SAT (sistema agrario tradicional) fue prolongada por la despiadada historia nacional hasta finales de la década de 1950; en las dos décadas siguientes fueron eliminados los elementos menos productivos para concentrarse en sus potenciales óptimos, de tal forma que si el SAT se simplificó en sus funciones productivas, mantuvo la complejidad en uno de sus subsistemas, el ganadero, que llegó a ocupar por completo el todo. Algunos rasgos de éste pervivían más o menos marcados dos décadas después (Rodríguez Gutiérrez, 2001, p. 22). Entre todos ellos, resaltaba el carácter múltiple del saber ganadero tradicional, oficio refinado que casi llega a ser un arte, el de hacer producir un ternero por vaca y año. Toda una ciencia la que se necesitaba para que el ganado comiera bien y sólo con los recursos del medio. El manejo formaba el sistema y requería conocimientos muy variados, que el profesional absorbía «respirando» el ambiente impregnado de una cultura milenaria, que se transmitía por instituciones tradicionales locales; con esas externalidades el ganadero «aguantaba» a pesar de que los rendimientos de las explotaciones eran mínimos para unas condiciones laborales muy físicas (Rodríguez Gutiérrez, 1989, p. 28).
Pero a comienzos de la década de 1980 todo cambió. La contención se perdió, la dinámica se aceleró y la tensión contenida en el muelle territorial proyectó a un futuro de disolución aquellos rasgos que contumazmente habían mantenido el sistema agrario tradicional, que llega al final de su ciclo.

La modernización encaja con dificultad en algunos territorios de montaña un nuevo sistema industrial o urbano, y en otros, a falta de alternativa, el SAT se disuelve y deja inerme, vacío y sin funcionalidad a ese territorio. El proceso se registró en Asturias, pero también en otras montañas españolas, que conocen en esta década su segunda y fulgurante transición demográfica, que las lleva a la desvitalización a través del envejecimiento. La tradicional sobrepoblación de la montaña hizo que la emigración siempre se dejara sentir como medio de ajustar la difícil relación entre población y recursos. Aunque la marcha a la ciudad y a la industria fue conocida, no trastornó decisivamente el proceso de cambio o de desarrollo del SAT, lo graduó, pero las narrias y las varas de hierba o la venta de los terneros en las ferias de otoño siguieron siendo utilizados y frecuentados. La cuestión se disparó a mitad de la década de 1980. Algunos dirán que fue la entrada en la Unión Europea, otros el nuevo estadio de integración en la civilización actual; hay quienes lo concretarán en los procesos de urbanización-metropolitanización, y habrá quien lo atribuya a la nueva mentalidad de una sociedad donde el trabajo físico ya no es la característica y si el consumo.

España incorpora la atención a la montaña en su legislación de la década de 1980 y no sólo como emulación de la legislación europea, sino por el impulso de organizaciones sociales montañesas que reclamaban una visión holística de estos territorios. Son los Grups de l'Alt Pirineu, es la movilización que se desencadena con las primeras asociaciones de montaña, como la que desde Asturias logra reunir en Lena las Primeras Jornadas de los Municipios de Montaña de la Cordillera Cantábrica en 1995, a las que siguen otras en Granada, Segovia... La movilización por la montaña es coetánea a su declive como sistema social dinámico y es tanta la importancia que se le concede, que son varias las leyes y disposiciones autonómicas que se promulgan para apuntalar ese interés. Son leyes como la 2/1983 de 9 de marzo de Alta Montaña de la Generalitat de Cataluña, más o menos paralela o convergente con la ley 25/1982, de Agricultura de Montaña, aprobada por las Cortes Generales el 30 de junio, que, curiosamente, no oculta la creencia en la imposibilidad de esta agricultura para desempeñar una función económica, pero reconoce su función social, y 
a tal fin refuerza su vertiente asistencial, polarizada en las explotaciones, dejando de lado la visión estratégica, apuntada en los programas integrados, que no se concretan; quizás porque la entrada en la UE planteaba el futuro de la montaña dentro del futuro del mundo rural (Сом 88/501), siendo el enfoque Leader el que desde 1990 se emplea para todo el desarrollo rural. Con las distintas formas de transferencia de rentas (indemnización compensatoria, ayudas agroambientales, subvenciones específicas para la Red Natura 2000, asistencias para el fomento del bienestar animal, las primas a las explotaciones lecheras, los subsidios a las explotaciones con razas ganaderas autóctonas en régimen extensivo, además de otras medias agrarias de carácter general) el proceso de cambio adopta la forma de disolución, quemándose el sistema agrario tradicional como la pólvora mojada, sin ruido, y sin apenas humo, mediante el aporte de rentas redistributivas que se transfieren a los titulares de las explotaciones; transferencia justificada en la necesidad de compensar los costes especiales que para ellos tiene el compromiso de ejercer una actividad beneficiosa para la montaña y para la sociedad en general.

Con la perspectiva que da el tiempo quizás podríamos representar lo sucedido como un inmenso tsunami que en unos pocos años de la década de 1980 desmanteló las estructuras en las que se organizaba la vida tradicional en la montaña rural. Cuando la inmensa onda de acción se retira, quedan como náufragos asilados en el inmenso territorio desmantelado algunas explotaciones más o menos aisladas, a las cuales se da asistencia mediante periódicos reabastecimientos que, en forma de subvenciones, vienen a completar su cuenta de resultados. No hay un plan general para reconstruir el territorio nacional. Las competencias estructurales en esta materia se regionalizan de acuerdo con una cierta interpretación de principios constitucionales. El problema es de gobernanza, y con Romero y Farinós (2006) compartimos la idea de asociarlo a importantes déficits de coordinación y cooperación en la configuración general del Estado español que por ello no supo reaccionar ante un problema de semejante magnitud. Se produjo una reconversión, pero no se preparó la necesaria reestructuración del territorio, como proceso inteligente y de carácter estratégico para conducir y controlar la recomposición del mismo en las nuevas condiciones. En 1990 en Asturias sólo las indemnizaciones compensatorias de montaña beneficiaron a 18.230 explotaciones (Rodríguez Gutiérrez, 1993), mientras que en 2010 todas las medidas de ayuda específicamente relacionadas con la agricultura de montaña se aplicaron a 7.000 beneficiarios, por un importe 23,2 millones de eu- ros, lo que da idea del retroceso y del menguado impacto que la política asistencial tiene en el contexto general del problema y su insuficiencia para proteger a los sistemas territoriales de montaña del tsunami demográfico que se les vino encima.

\section{LA DESVITALIZACIÓN ES EL PROBLEMA DE LA MONTAÑA TRADICIONAL Y NO DE TODA LA MONTAÑA. SÍNTOMA DE FRAGMENTACIÓN Y AMENAZA PARA LA COHESIÓN}

Considerando a Asturias como región paradigma de la montaña, físicamente hablando, trataremos de perfilar las características de sus modelos de poblamiento y demográfico para definirla como referente demográfico de las regiones de montaña. Evidentemente no es único, pues, por ejemplo, se trata de una región litoral y no continental, pero sirve para cualificar la fuerza de la tendencia demográfica de más pura determinación montañosa y para reflejar los contrastes dentro del espacio clasificado como montaña.

Asturias podemos considerarla como una isla, de forma aproximada rectangular, en cuya franja costera (12\% de la superficie), a menos de cinco kilómetros de la ribera, reside el $46 \%$ de la población; en el área metropolitana interior otro $45 \%$ (que ocupa el $23 \%$ territorio) y sólo el $9 \%$ de la población (88.064 habs.) en los dos tercios del territorio interior y montañoso, que constituye el borde cumbreño meridional.

Si en ese mismo rectángulo representásemos las densidades, tendríamos un núcleo metropolitano con tres centros de gran densidad (más de 1.000 habs. $/ \mathrm{km}^{2}$ ), unidos por un tejido urbano de 120 habs. $/ \mathrm{km}^{2}$, y en la costa una franja de escasa manga con densidades de 50 habs./ $\mathrm{km}^{2}$. El resto, interior, montañoso y vacío con densidades inferiores a los 15 habs. $/ \mathrm{km}^{2}$.

Por tanto, como rasgos de la distribución de la población en una región paradigma como es Asturias, observamos la metropolitanización, la litoralización y la desvitalización interior. En un segundo plano, la diversidad que induce la fragmentación regional y contrastes acusados en el interior de todos los municipios, ya sean metropolitanos o rurales, en los que aguantan las plataformas ciudadanas conocidas como villas. Aparece una nueva categoría, los municipios de clímax natural, en los que el residuo civilizante no se presenta como elemento funcional sino como puesto avanzado.

Las características demográficas de este modelo de asentamiento de la población en Asturias las apuntala- 
FIG. 4. Distribución de la población por zonas y áreas en Asturias en 2013.

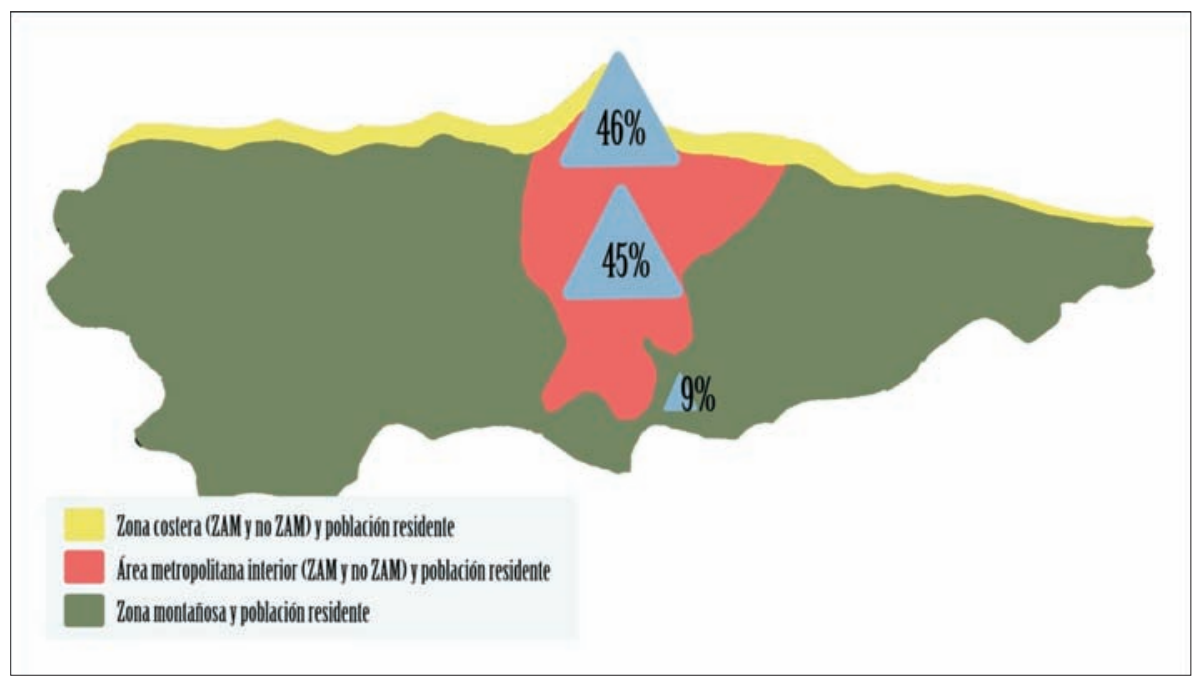

mos con los datos procedentes de tres fuentes: Sadei (2013), PDR del Principado de Asturias (2014) e informe RegioLab (2014), según las cuales se constata que:

La tendencia desvitalizante no pierde inercia, al contrario su fuerza se incrementa. Pues en los últimos seis años sólo tienen un comportamiento positivo los concejos metropolitanos y algunos costeros.

Los movimientos migratorios internos tienen más significado que los externos e incentivan la concentración En 2012 se mantiene la pulsión atrayente de los cuatro grandes municipios metropolitanos (Oviedo, Gijón, Avilés y Siero) a costa de los demás.

La tasa de natalidad baja, seguirá enfriándose, y ya alcanza el cero absoluto en los municipios más enclavados, montañosos y sin villa. En 2012 la tasa de natalidad en Asturias $(7,12 \%$ ) es más baja que la española $(9,69 \%)$; aún así, hay 59 de los 78 concejos que están por debajo de la media, y en varios es del $0 \%$, todos son ZAM.

La tasa de mortalidad se dispara en el proceso final hasta niveles sorprendentes En 2012 en Asturias era del $12,3 \%$ mientras que la de España era del 8,6\%o; sin embargo, 60 de los concejos interiores y montañosos tenían una tasa del $20 \%$.

El crecimiento vegetativo será muy contratado entre las regiones y localidades de montaña radical, tomando rumbos divergentes las motoras y las desenganchadas o en integración El crecimiento vegetativo en 2012 para España era del 1,12\%o, para Asturias del $-5,16 \%$, y nada menos que entre el -15 y $-23 \%$ se alcanza en 13 concejos interiores y de montaña, los «sin villa».

Por todo ello, veremos una sociedad de viejos, desalentada para luchar por proyectos de futuro. El índice de vejez en Asturias $(2,11)$ es mucho más alto que la media en España $(1,08)$ y hay 19 concejos interiores y zAM (oeste y este del área metropolitana) que tienen índices de entre 5 y 11.

Que son agentes netos de gasto y dependientes de las rentas redistributivas que ellos generaron y de la solidaridad de los demás. El índice de dependencia fuera de la costa y del área metropolitana llega a sobrepasar el 80\%; es decir que por cada diez personas en edad activa hay ocho dependientes, normalmente ancianos.

Pero no todo es negativo en este panorama demográfico. Existen las villas, los pequeños núcleos urbanos que concentran las actividades comerciales y de servicios, así como los equipamientos destinados a la población residente en ellas (entre 1.000 y 7.500 habs.) y en sus áreas de influencia (en general menos de 25.000 habs.) que en la montaña son pequeñas y muchas, por lo que ocupan regularmente el territorio.

La dimensión de las áreas de influencia y la política de asignación de equipamientos de alcance supramunicipal por parte de las administraciones regionales han contribuido al aumento de las diferencia entre las villas, pero también las han estabilizado. Las más enclavadas y en un territorio interior sin reestructurar experimentan las debilidades del mismo. Las cercanas al mundo metropolitano tienen una dimensión notable y mejores tendencias demográficas y económicas. Otras han sido impulsadas y ellas mismas son vectores de la reestructuración territorial, mediante el turismo, la atracción residencial, la mejora de los equipamientos, los servicios públicos y el desarrollo urbano. Las villas de influencia solamente municipal son de pequeñas dimensiones, 


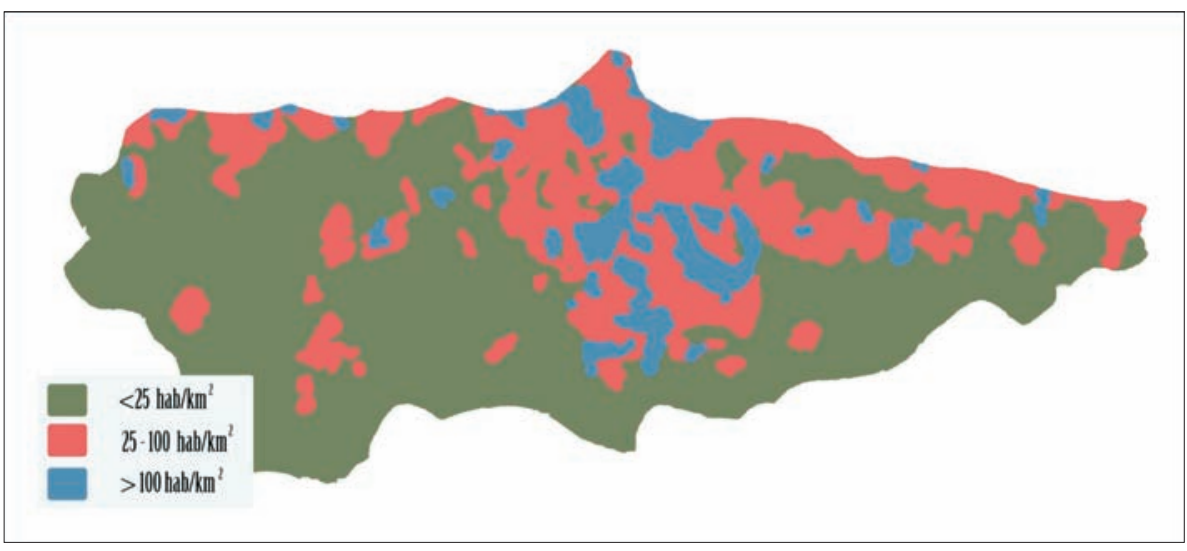

FIG. 5. Densidad de población por parroquias en Asturias en 2010.

presentan una peor evolución y unas funciones urbanas limitadas.

En cualquier caso, las villas tienen un papel fundamental en el sistema territorial montañés, como enganche entre el mundo metropolitano y el poblamiento rural y contribuyen de manera decisiva a la ocupación dinámica de la montaña. La función actual de las villas no sólo es la tradicional de proveer de servicios a su constelación aldeana. Hoy su horizonte de supervivencia está mucho más lejos y debido a las mejoras experimentadas en los últimos años parecen preparadas para alcanzarlo.

Por lo dicho, se debe reconocer la relevancia que para la identidad, la cohesión y el desarrollo regional tiene el territorio de montaña que, en general, es manejado por una escasa población, cuyas perspectivas demográficas constituyen el problema. El asunto se convierte en importante para España y esencial para algunas regiones, como Asturias o Cantabria que, precisamente por ello, deberían desligar montaña y agricultura de montaña, pues realmente no pueden ni deben unir en exclusiva el concepto de montaña a lo agrario, que apenas si aporta un pequeño porcentaje de la renta y del empleo regional, aunque la dedicación agraria sea relevante localmente; ni a lo rural, pues parte de la vida de la comunidad más montañesa se desarrolla en entornos urbanos y metropolitanos. De hecho, en ciertas regiones de montaña existe una economía industrial y de servicios muy potente que se ha encajado en el medio montañoso con dificultades y éstas, en parte, vienen de no haber encontrado modelos de ordenación del territorio adaptados a la original identidad regional, que permitan la integración complementaria de funciones muy distintas, quedando oscurecidas las relacionadas con la montaña bajo el brillo de la homogeneidad urbana.

\section{UNA PROPUESTA: DIEZ MEDIDAS PARA MANTENER OCUPADA DINÁMICAMENTE LA MONTAÑA IBÉRICA}

Como sistemas, los territoriales cumplen leyes comunes, y se diferencian de otros como, por ejemplo, los biológicos en que no mueren. Pero, por si esto no fuera cierto, conviene encontrar actividades industriosas adaptadas a la montaña, ya sea metropolitana, urbana, rural o de clímax naturalizante. Esta adaptación la concretamos en una línea de actividades a partir de las capacidades generales de los territorios de montaña para definir un modelo productivo que puede aplicarse en una buena parte de ellos y al que denominamos economía de la identidad, basado en las capacidades del lugar, que no sólo incluye sus potenciales, sino también sus derechos y la funcionalidad que al interés general cumple. Esas capacidades son la aportación que la escala local hace al juego multinivel para integrarse en los sucesivos órdenes espaciales donde se encaja en Europa, y es también el enfoque de la Agenda Territorial Europea 2020, que allí se denomina place-based approach como fundamento de una política territorial activa por la cohesión y para control el cambio en el bloque continental (ATE 2020, 2011).

¿Se está a tiempo de mantener ocupada a la montaña? La respuesta se contenía de manera explicita en una la faceta estructural de la ley de Agricultura de Montaña, que por diversas razones no se desarrolló, ni en las comunidades autónomas que seguían el régimen general, ni salvo alguna excepción en las que siguieron regímenes específicos. La posterior iniciativa comunitaria Leader vino a incidir en la respuesta: movilizar a los actores económicos y facilitar su organización sobre una base territorial para crear una dinámica de proyecto en el nuevo contexto mundial. Esta respuesta sigue siendo válida; aunque hoy el 
problema demográfico se ha agudizado y la cuestión llega a ser en muchas localidades ¿a quién movilizar?

La tendencia en la mayor parte de las montañas conduce a la desvitalización y es fuerte; combatirla requerirá de algo más que voluntarismo espontaneísta, necesitará de lógica de proyecto, como método para la acción territorial pertinente, inteligente, organizada en un modelo coherente. El que aquí se apunta tiene una finalidad: «mantener ocupada dinámicamente la montaña»; su objetivo: generar actividad industriosa adaptada a las capacidades de los territorios rurales de montaña; el método: la economía de la identidad, entendida como la que proyectan las regiones capaces de reunir su «capital inmaterial» (saber, talento, experiencia, sensibilidad, cultura, relaciones humanas) con su «capital relacional» (imagen, propiedad industrial, redes, relaciones con el medio físico o entorno y con los valores que inspiran sus decisiones) para obtener nuevos productos.

A continuación se expondrán un decálogo de medidas que se contienen dentro del sintagma economía de la identidad y que son complementarias a las de contenido agrarista que tienen como sujeto la explotación ya sea agrícola ganadera o forestal.

\section{Buscar nuevos MOdelos de Gestión terRitorial BASADOS EN LA LÓGICA DE PROYECTO PARA TOMAR EL CONTROL DEL PROCESO DE RECOMPOSICIÓN DEL TERRITORIO INDUCIDO POR LA DESPOBLACIÓN}

El problema es territorial, de descohesión o desenganche de amplios territorios que vienen determinados por su naturaleza montañosa. Se han experimentado soluciones, focalizadas por ejemplo en las asistenciales dirigidas a las explotaciones agrarias. No han dado resultado. El problema es más amplio y se trata de reconstruir un modelo de gobernanza territorial ante la quiebra del esquema hasta ahora utilizado, aunque éste también ofrezca una amplia gama de buenas prácticas. Pero el problema de la montaña es también un problema del tiempo actual, un asunto de los que Habermas clasifica dentro de la «gramática de la vida» del mundo que hoy toca vivir, en el que se necesitan formas de integración que anuden las relaciones que cohesionan a los territorios, que enlacen las diferentes escalas en las que estos juegan, para facilitar la participación pertinente del mayor número de actores y la cohesión del territorio como forma de relaciones que da la especificidad el modelo europeo.

Ante la dimensión del problema hay que actuar, sabiendo que los efectos de la mundialización dan lugar a nuevos modos de desarrollo que ofrecen una oportunidad para demostrar la necesidad de la montaña. El gran juego global que desmaterializa la actividad económica hace que ésta pase de la repetición a la búsqueda de la diferencia, de la cantidad a la calidad, de la producción a la innovación, de las necesidades a los problemas. Todas son bazas que el juego global ofrece a los territorios y, entre ellos, a los de montaña; por ello, la nueva gestión territorial deberá tener en cuenta que la empresa necesita poner la vista fuera de sus muros para trabajar con la inteligencia regional y utilizar las capacidades territoriales para diferenciar sus productos, muchos de los cuales pueden estar ligados a la imagen de autenticidad. El juego territorial las burbujas participantes lo siguen con su saber y organización peculiar. El ciclo que ahora se abre reclama la lógica de proyecto, que enlace la visión estratégica (con un proyecto donde se formule la ambición compartida para el territorio a largo plazo, enfocado de manera transversal hacia los problemas); la dirección táctica (a medio plazo, sectorial, con la que acompañar los proyectos empresariales y sociales) y la acción operativa (basada en la inteligencia territorial, captada mediante la participación permanente, el trabajo con las vanguardias portadoras de proyecto y la acción simplificada de la administración). La concreción de las formulaciones estratégicas podrá hacerse mediante métodos operativos de animación y seguimiento, adaptados a la realidad de sus participantes, dotados de capacidad ejecutiva, información apropiada, libertad de decisión y esferas competenciales propias. Por eso creemos que la aplicación del el método abierto de coordinación (Villeneuve y Rodríguez Gutiérrez, 2002) es un buen complemento a las visiones estratégicas, con el fin de asegurar que la belleza de su diseño se concrete en alguna medida; operativamente, a lo largo de un ciclo temporal medio.

La nueva política para la montaña no puede limitarse a ser subsidiadora. Esta orientación ha calificado a una etapa superada. Alcanzar su objetivo de recrear un territorio geográficamente activo va requerir más que la faceta asistencial; pero la administración pública en la que escala de la Unión o en la nacional, no puede retirarse de esta lucha, deberá hacer-hacer, ordenar, invertir, integrar y simplificar. El problema de la montaña es, por una parte, de ordenación y del territorio y desarrollo regional, para facilitar externalidades y de redistribución de recursos. De recrear una atmósfera adaptada a las capacidades del lugar, en la que se garanticen servicios, oportunidades, autonomía, interacción personal y ruptura de la soledad. Las medidas de ayuda a los titulares de las explotaciones agrarias son insuficientes para lograr las fi- 
nalidades perseguidas, como es contener su desaparición y, desde luego, están muy lejos de contribuir significativamente al objetivo general de revertir la despoblación. Simplificarlas, concentrarlas en paquetes integrados, mejorar su aplicación para aumentar su impacto pueden ser medidas que las optimicen, pero no pueden plantearse en exclusiva. Deberán combinarse con las provenientes de la política de cohesión territorial destinadas a todos los residentes y al territorio, a facilitar la integración del territorio de montaña en el regional mediante políticas de ordenación y desarrollo regional que aseguren la eficacia de la acción inversora pública. Los sujetos de este modelo son las unidades territoriales básicas, las burbujas locales, pero ello no quiere decir que sean municipales, o que esas unidades de acción se tengan que ver restringidas por fronteras autonómicas, pues por definición la montaña es una región con dos vertientes, que está recomponiéndose por el juego de nuevos procesos.

En términos de modelización cada unidad local es un sistema territorial compuesto por los elementos participantes y por las relaciones que establecen entre si; es precisamente esto lo que los distingue, las relaciones cooperativas que los participantes establecen y con las que forman las paredes del triángulo mágico territorial, imagen con la que representamos metafóricamente a tales unidades, en cuyos vértices situamos, institucionalmente agrupados, a los actores de la economía, de la socialización y del conocimiento. Dependiendo del modo en que se organicen las relaciones entre ellos y con su medio, el sistema territorial es capaz de desarrollarse, de apuntar hacia un nuevo horizonte en el constante juego de la vida. Como hablamos de la dimensión territorial de la vida no consideramos equivalentes los términos territorio y espacio. El territorio es el espacio cargado de valores ciudadanos, con los cuales se organizan las relaciones en el interior de una unidad, con las otras y con el medio. Por ello, la cantidad de territorio que contiene un espacio dado puede aumentar o disminuir, dependiendo, en parte, de la acción excelente de sus actores, que, teniendo un sentido pertinente de sus problemas, son capaces de orientar una visión común acerca de un proyecto viable.

La despoblación induce la recomposición del territorio, pues el esquema anterior se desajusta y el territorio evoluciona hacia espacio de clímax natural. Como sistemas, los territorios tienen sus propias especificidades; por ejemplo, cuesta mucho certificar la muerte de un territorio; los territoriales se separan de los cibernéticos por no tener estados-meta claros y se diferencian de los sociales en que no son simplemente la arena donde se desarrolla el conflicto, ellos lo pueden ocasionar. Tam- poco territorio es equivalente a espacio geodésico, pues dadas las mismas coordenadas, en un determinado momento podemos encontrar un clímax de plenitud, caracterizado por equilibrio, productividad, libertad, seguridad y autonomía, y en otro una situación de desajuste, con alteraciones a la baja y pérdida de los valores ciudadanos, hasta hacer peligrar la condición de territorio, ya que no está presente la acción humana ejercida a través de los tres nodos institucionales locales ni las relaciones entre ellos se efectúan como contribución al capital social. Son los espacios donde sus relaciones se mantienen en un clímax natural. Es la tendencia hacia la que avanzan las montañas del noroeste ibérico, algunas pirenaicas o del sistema ibérico.

La recomposición de los territorios implica que en unas condiciones de civilización, el espacio pueda ser ocupado de otra manera, redefiniéndose así los límites de lo local. El asunto es tener bajo control el proceso de recomposición territorial. Clasificarlo como espacio protegido puede ser una parte de la solución de control. Así se garantizan unos ciertos recursos pero no todos los que puede proveer la montaña viva, dinámicamente ocupada como proveedora de servicios en el sentido que establece MEA (2005) En Asturias la superficie protegida supone el $54 \%$ del territorio regional. Sólo con ella se garantizan tales servicios ¿cuál es el interés territorial de Asturias?

La desertificación no sólo supone la eliminación del participante local, que podría ser reemplazado, sino que afecta a las capacidades que permiten utilizar plenamente las potencialidades de un territorio. Capacidades territoriales son las condiciones presentes en el territorio que pueden realizarse efectivamente, utilizan sus potenciales, los derechos a hacer y la voluntad de la gente comprometida con un proyecto de desarrollo. Las capacidades del territorio no se inventan, sino que se descubren y se manejan con mayor o menor conocimiento. Son una mezcla de poder y querer, constituyen el estado actual de la cuestión y por su carácter dinámico deben ser movilizadas para protegerse del riesgo previsible mediante la lógica del proyecto (Salais y Villeneuve, 2004; Rodríguez Gutiérrez, 2004).

\section{Considerar la montaña COMO bioma PROVEedor \\ DE VALIOSOS RECURSOS PARA LA VIDA Y CONSIDERAR LAS UNIDADES LOCALES COMO UNIDADES DE ORDENACIÓN DEL TERRITORIO MÍNIMAS}

El territorio de montaña tiene como rasgo la diversidad. La variación altitudinal da lugar a varias zonas bioclimáticas en una misma montaña. La humanización de este 
espacio se ha hecho teniendo en cuenta tal determinación, haciendo surgir un complejo geográfico, básicamente agrario que utilizaba el potencial de los biomas presentes para crear un sistema de utilización de las capacidades territoriales. Así en paralelo a la zonificación bioclimática se daba una regulación agronómica para respetar el ciclo natural y obtener el óptimo rendimiento del mosaico territorial, en el que los biomas se sitúan en bandas irregularizadas por circunstancias locales (exposición...) y estrechas, tanto como los ecotonos. Todo provoca diversidad y facilidad para el intercambio, siempre más fácil en sentido descendente, aunque el seguimiento del ciclo solar también impulsa los movimientos ascendentes.

Estos intercambios energéticos circulares se realizaban dentro de una unidad territorial mínima que aseguraba su funcionalidad, complejidad y rendimientos en la medida que manejaba mayor número de pisos bioclimáticos. Las determinaciones del sistema natural las reconocía el sistema social que por ello hacía que se compartieran los derechos sobre la tierra entre las comunidades locales y los poderosos, estableciéndose particulares regímenes jurídicos de la propiedad. Por tanto los derechos sobre la tierra partían de una base natural que aseguraba la reproducción funcional del sistema y de una base social, la de la época. Hoy la base social ha cambiado y mucho menos la base física, por eso es importante identificar estas unidades de gestión tradicional del territorio de montaña que se han mantenido más menos inmutables a lo largo de milenios y en las montañas de cualquier parte del mundo. En el mundo atlántico europeo son las feligresías o parroquias, que en el mundo peninsular también aparecen como concejos, en un caso de vecinos y en otro de parroquias.

La implantación de actividades polarizadas que aparentemente no necesitan tener en cuenta estas condiciones ha sido factor de trastorno y su impacto ha alterado los sistemas de intercambio.

Normalmente la regulación se ha efectuado en las montañas españolas en tres grandes zonas agronómicas que se incluían dentro del perímetro de las células de ordenación del territorio, definido por la jurisdicción (casi nunca total) de una comunidad local que, como núcleo rector funcional, residía en la aldea o aldeas, situadas en general a media ladera de las vertientes bajas, y desde las cuales el sistema de intercambio se reglaba, definiendo varios espacios agronómicos. En primer lugar y a su alrededor, en lo que en el llano serían los aros de la aldea, hombres y ganado competían por los mismos recursos, el espacio estaba intensamente aprovechado y estrictamente regulado, por arriba su raya la trazaban las últimas tierras de cultivo temporal y los primeros espacios pascícolas, que definían un piso de transición de función logística en el ciclo ascendente-descendente, siendo su ocupación dominante el bosque con espacios de pasto o de cultivo de baja producción. El límite del bosque da la raya superior en la que hombres y ganado ya no compiten y el pastizal sólo es aprovechado en una parte del año y desde cierta distancia. En cada piso las irregularidades y el gradiente altitudinal dan plantas hasta llegar a la cumbre agronómica que se alcanza en una determinada fase del año para comenzar el descenso gradual.

En estos momentos los procesos de abandono y desactivación funcional amplían la importancia del bosque, a costa del espacio pascícola, ya sea de diente o de siega, pasando a ser el bosque la formación dominante en los pisos inferiores, siendo por tanto el recurso forestal uno de los elementos a considerar como base de un aprovechamiento productivo y como elemento regulador del ciclo hídrico y protector del suelo y de las especies y embasteciéndose el pasto en los superiores. No obstante, sigue siendo válida la consideración de la gestión montana a partir de células mínimas o básicas de ordenación del territorio, las células tradicionales, adaptadas a las necesidades derivadas de la crisis demográfica para poder preservar su esencia de territorio, encajadas armónicamente en las de menor escala, soportes integrales construidos culturalmente para garantizar los procesos y la función de reserva general de la montaña y soporte de nuevos desarrollos adaptados a su configuración geográfica en pisos.

Por tanto, estas células recompuestas, asociadas, deberán seguir funcionando como plataformas resilientes para sostener nueva actividad conforme a la esencia de las pautas de gestión. La fórmula de reconocimiento deberá ser estudiada pero figuras como los parques rurales o históricos son una forma de garantizar el mantenimiento de actividades industriosas sobre la plataforma tradicional, que lo será también por conservar las praderías de siega y diente, importantes patrimonios amenazados por la expansión del bosque y por el embastecimiento y que como patrimonio semi-natural son un importante reservorio de riqueza florística que en España no se ha perdido por la intensificación y cuya recuperación en este planteamiento de unidades locales no será costoso y si justificado.

\section{Crear una nueva acción territorial para la MONTAÑA Y NUEVOS PROFESIONALES PARA PRACTICARLA}

Controlar el cambio del territorio es casi una utopía, pero orientadora de la acción; es también una obligación del poder público y, probablemente, una necesidad sis- 
témica. Si esto fuera así, se necesitaría una disciplina y unos nuevos profesionales para la intervención territorial, que, dotados de un conocimiento y una deontología específicos, trabajen ayudando a controlar la recomposición territorial, al lado y un paso por detrás de los verdaderos protagonistas del mismo, las distintas comunidades que forman las unidades territoriales básicas. Que se aspira a que sean burbujas territoriales enraizadas armónicamente en su ambiente local y enlazadas tecnológicamente con otras en los sucesivos niveles de un proyecto cultural e identitario compartidos.

Esa nueva disciplina (que reactualiza la geografía y la pone de nuevo ante la necesidad de explorar el mundo, aunque sea el más próximo; difundir la cultura territorial, para cuidarlo; y colaborar en su gestión) utiliza como instrumento técnico el proyecto. Por eso, llamamos «lógica de proyecto» al conjunto de destrezas y valores que se utilizan para trabajar eficazmente por el control del cambio territorial o desarrollo, de acuerdo con las capacidades del territorio y con una mentalidad estratégica al servicio del interés general; definido en las distintas escalas o niveles de decisión en el que está inmersa cada unidad territorial.

Para practicar esta nueva disciplina son necesarios nuevos profesionales que la hagan operativa. Pero no hace falta inventar su oficio, está en la tradición geográfica, la que hizo cartógrafos, pilotos, cosmógrafos, navegantes, exploradores, naturalistas o historiadores. Llamémosles como quiera la época. La actual sigue reclamando conocimiento y aventura, los que Humboldt utilizaba para comprender el funcionamiento integrado del territorio; pretensión de siempre y que ahora reclama la sociedadred en la que «Lo que es seguro es que tener una educación universitaria deberá suponer habilidad para manejar el cambio, la colaboración, la sobrecarga de información y la incertidumbre», dice la profesora Cathy Davidson de la Universidad de Duke (EE. UU.); y añade: «[...] eso requiere una fusión de disciplinas [...]. En los desafíos del mundo real, está cada vez menos claro donde termina una disciplina y comienza otra» (Pérez Díaz, 2010).

Y para todo eso hay que tener método y juventud, y ellos pueden ser la aportación que haga la universidad en uso de su tercera función: la cooperación al desarrollo territorial (Rodríguez y Villeneuve, 2001, p. 294). La misión de la universidad es universal, está implícita en su nombre; por ello, su compromiso local debe interpretarlo a la luz de su finalidad última, aunque su objeto esté a unos kilómetros y no en la costa más lejana, pues todos los territorios están en vías de desarrollo; por eso se necesitan profesionales que actúen, más que como inefables técnicos, como contrabandistas del conocimiento, que producen y trasladan valiosa información entre los distintos participantes locales y se enfrentan a los demagogos locales, garantizando su independencia la sociedad, como elementos de un proceso ilustrado general, en el que la formación de teoría es un paso, que dan los que de ella libremente se ocupan, y la lucha política otro, encargándose estos profesionales del intermedio, la organización de procesos, en los que se pueden utilizar las teorías, que este escalón ajusta a las opciones pertinentes que tienen los interesados y que son elegidas en el tercero mediante la decisión política (Rodríguez, 1989, p. 75).

Así encuadrados profesionalmente estos activistas del desarrollo o evaluadores territoriales no son un contrapoder sino un elemento más del proceso emancipatorio de un sociedad ilustrada, en la que la universidad impulsa una sociedad universal mejor ordenada. A esta obra los evaluadores territoriales contribuyen mejorando la calidad del capital social de la unidad territorial y co-proyectando formulaciones y planes, con el fin de anticipar su modelo territorial de futuro. Para ello captan la inteligencia territorial mediante la participación organizada, amplían las capacidades territoriales mediante la adición de elementos de valor, y buscan referencias de especialización inteligente donde las haya. Y con ello generar actividades productivas ejecutables en el mercado, apoyadas por máquinas herramientas territoriales capaces de producir externalidades.

Se trata de mantener ocupada activamente la localidad, burbuja territorial o triángulo mágico territorial, haciendo que la composición de su renta esté equilibrada. Que no dependa mayoritariamente de la transferencia de rentas redistributivas, sino que alcance un nivel de renta como producto de las directamente productivas más que de las asistenciales. Así se evitarán patologías sociales y se alentará el afán de lucha por la vida. Para ello es importante la naturaleza del capital social, como producto de los valores ciudadanos, el cual facilita las visiones comunes y alinea el esfuerzo de los participantes de cara a una ambición compartida, siguiendo una lógica de proyecto, vertebrada en fases sucesivamente enlazadas: inquietud, ante el problema percibido; formulación de ideas, que expresan las esperanzas, muestran las competencias y organizan la reflexión para acercar puntos de vista y permitir el tercer paso, la elaboración del proyecto, a cuyo través se estructuran los intereses, se descubren las capacidades, se definen las prioridades, se organizan los recursos, se diseñan estrategias y cooperaciones y se crean alianzas, para que en la cuarta fase, la de la gestión, los actores locales pongan a prueba sus responsabilidades, comprueben las 
posibilidades de sus capacidades, entiendan los intereses de otros grupos y asuman los riesgos que conlleva decidir para alcanzar nuevas oportunidades. Una quinta fase, paralela a la anterior, es la seguimiento, animación, alineación de esfuerzos y voluntades entre pares, para la que recomendamos el método abierto de coordinación.

\section{VIVIR LA MONTAÑA}

Puede ser la formalización del compromiso de la Administración con el ciudadano y con el territorio montañés. La constatación de que a pesar de que el temporal arrecie no va a ser abandonado por parte del servicio público, por el interés general que ocupar la montaña tiene para el país

Puede ser el lema que identifica una suerte de «partenariado», formado por el Gobierno, con las comunidades locales, grupos y empresas de interés general, organizaciones de productores y la universidad, agrupados territorialmente en nuevas formas de gestión participativa para co-proyectar operaciones estratégicas de desarrollo, a las cuales se transfieran los recursos que son la base de actuación de ese pacto de solidaridad. Esta es el esencia de la iniciativa Leader y se puede decir que ha funcionado bien. Profundizar en el método es una apuesta segura. Modificar la escala de la unidad una necesidad. Pero hará falta más a no mucho coste. La creación de plataformas de acompañamiento que cumplan su misión dentro de una formulación estratégica con visión a medio-largo plazo no será cara. Y su soporte financiero puede venir dado por la posibilidad que ofrece la política de desarrollo rural de la Unión Europea para el periodo 2014-2020 de ofrecer un apoyo especial a las zonas de montaña en forma de subprogramas específicos de carácter temático. Ésta es la recomendación que hace la ATE 2020 (2011, p. 28) y que algunas comunidades autónomas ya están poniendo en marcha como es la de Castilla y León con su programa Agrohorizonte 2020, formulación estratégica focalizada sobre siete sectores agrarios que intenta utilizar la financiación contenida en el actual periodo de programación europea que bien podría ampliarse a empresas de interés general y basadas en el aprovechamiento de recursos locales como las energéticas.

\section{Mantener las Villas es REFORZAR El POLICENTRISMO A ESCALA REGIONAL AMPLIANDO SU HORIZONTE}

Las villas constituyen la esencia urbana del mundo rural. Son plataformas de vida y actividad que durante siglos sirvieron y se nutrieron de su ante-país rural y son la evidencia de una positiva realidad policéntrica patente en la escala regional.

Hoy las villas de la montaña son el baluarte en la ocupación del territorio y las plataformas de una nueva actividad. En ellas es básica la acción de la administración pública que desde allí concentra su actividad y es esencial que frente al debilitamiento de su hinterland rural eleven su mirada hacia fuera pues, en general, continúan siendo pueblas de urbana hidalguía que conforman un tesoro de pequeñas joyas urbanas, de las que hasta ahora dependía un universo de aldeas. Hoy la globalización puede concederles una baza pues su mercado potencial no se reduce a las aldeas vecinas sino que sus capacidades territoriales son el elemento atractivo que convenientemente procesado y difundido puede alcanzar clientelas muy lejanas. En su tipología y dinámica existen comportamientos muy dependientes del conjunto subregional donde se ubican, por lo que si se detectan las regularidades que explican evoluciones distintas, quizá sea posible orientar los proyectos de intervención en función de tales regularidades.

\section{Catalogar los núcleos Rurales}

Forman el eslabón más débil de la cadena de poblamiento. Admitiendo que por necesidades funcionales exista una pérdida en los núcleos ocupados, la operación de renovación de los pueblos es estratégica y puede comenzar a ser abordada a partir de la catalogación de los núcleos rurales, poniendo su referencia en la búsqueda de la calidad territorial, un asunto que necesita del diálogo social y de la participación, además de la reconstrucción de la imagen rural, el paisaje, cuestión de índole identitaria.

Se trata de añadir valor a los núcleos rurales. No se trata de abordar el asunto desde la perspectiva única de la conservación. Los pueblos siguen siendo contenedores de actividad y, por tanto, de vida, y hemos de garantizar alguna forma de funcionalidad. Se trata de que hay un universo de aldeas y es preciso determinar las diferentes galaxias y sus capacidades.

La disposición financiera bien podría venir de la puesta en práctica del principio de aprovechar las posibilidades de complementariedad entre diferentes políticas y medidas, promovidas por distintos operadores públicos que actúan en el campo de la vivienda, las infraestructuras, la formación o el empleo.... los cuales podrían establecer cuánto cuesta al promotor privado que actúa en un núcleo catalogado acceder al plus de calidad prescrito (en 
calidad de materiales, tipos de obra, cautelas técnicas...) y suplementar desde ellos, todo o parte del valor de ese plus que se induce.

La regeneración de los núcleos se plantea como un proceso. El resultado buscado será su mantenimiento como soporte de la vida social y económica, estimándose que la estrategia a utilizar para conseguirlo descansa sobre la identidad rural, a la que puede darse cobertura mediante la figura de parque rural, que engloba al núcleo rural y a su protoplasma en una unidad elemental de ordenación del territorio.

\section{FomentAR El ESPÍRITU DE COMUNIDAD LOCAL, EL INTERÉS EN POSEER, DEFENDER Y HABLAR}

Los ayuntamientos, entre otras misiones, expresan la voz de su comunidad; en tiempos de ajuste una medida de ahorro es su supresión, lo que acentúa la tendencia al despoblamiento. Ni los ayuntamientos de montaña son los responsables del déficit público ni parece que las medidas de fusión sean indicadas con carácter general para estas comunidades debilitadas. Otra cuestión son las fórmulas de cooperación comarcal y las soluciones que se den para aquellos municipios que prácticamente son parques al cuidado de funcionarios, a la vez que otros presentan en su interior comunidades dinámicas que mantienen una personalidad secular como componentes esenciales de los concejos vecinales, son las parroquias, cuyo espíritu comunitario debería protegerse. La ordenación del territorio en la escala local es aquí un ejercicio obligado que debe integrar el urbanismo en un proyecto más amplio, de desarrollo territorial.

\section{RECREAR EL ESPÍRITU DE REGIÓN GEOGRÁFICA}

Hay tendencia a fraccionar la montaña por la línea cumbreña, lo que no tiene un sentido absoluto, y hoy mucho menos, cuando tan baja es la carga demográfica; por lo tanto, por lógica funcional y por lógica de proyecto convendría alentar los proyectos de cooperación con espíritu de macizo; considerar las montañas como unidades regionales, saltando el efecto frontera, no sólo por un probable comportamiento similar a ambos lados, sino como una manera de crear nuevas centralidades de proyecto compartido. Nuevas centralidades consideradas en un a escala macro-regional o de cuadrante, entendidas como plataformas territoriales complementarias a las urbanas o metropolitanas orientadas a nuevas funciones es- pecializadas. En este sentido llamo la atención sobre las montañas del noroeste ibérico, las de la Gran Cantábrica: Asturias, Galicia, León, Zamora y Región Norte de Portugal, que constituyen el punto culminante y germinal de la raya fronteriza en la que los procesos generales de esta franja marginal se acentúan y para los que el proyecto de cooperación interregional es imprescindible. Apoyaría esto la evidencia, probada en algunos estudios, de que la relación existente por regiones entre la cantidad de los fondos estructurales recibida por habitante y la convergencia de las regiones retrasadas es, en general, débil. Lo normal sería que las más dotadas de fondos se acercasen a la región de referencia o a la media regional; otras, en cambio, mantienen su posición, pero con un montante de fondos similar a éstas últimas las regiones citadas se despegan en sentido contrario. Lo que apunta a que existen esquemas de convergencia o acercamiento entre regiones de carácter sub-estatal o macro-regional, determinadas por el contexto geográfico, económico e institucional propio de cada macro-región, lo que condiciona la distribución, la ejecución y el uso de los fondos estructurales utilizados, así como la creación de empleo, vital para el desarrollo regional. Estas nuevas centralidades podrían especializarse en actividades industriosas como las derivadas de:

\section{Cuidar la práctica de los deportes de aVentura, Y ENTRE ELLOS, ESPECIALMENTE, EL CICLISMO}

En los países ricos, a medida que el trabajo ha dejado de tener un componente físico, el deporte de aventura en la naturaleza vuelve a generalizarse para reencontrar a las personas con el esfuerzo físico, para el que la especie está programada desde sus orígenes (Diamond, 2013). La montaña es objeto de simbolización creciente, como medio diferenciado frente a la homogeneización generalizante, en el que cercanamente se encuentra el riesgo, el esfuerzo... y se vuelve a la noche para contarlo.

La montaña cuenta con recursos tangibles e intangibles asociados a la mítica deportiva; más allá de los deportes vinculados a la pendiente y a la climatología hay paisajes de elevada calidad, infraestructuras adecuadas, con una ocupación del territorio a partir de villas atractivas y una dotación de equipamientos hosteleros que podría atender las necesidades específicas de una demanda exterior de escala mundial, que busca una práctica segura, en escenarios significativos y bien atendidos. Existen destacables trabajos que estudian los deportes de aventura y su impacto territorial en España (Lacosta, 
2001) y demuestran que hay mucho recorrido por delante. Existen inversores particulares que apuestan por la actividad en este sector, y hay un relativo interés público. Lo mismo que se clasifican espacios por sus valores ambientales o paisajísticos también otros pueden ser escenarios de alta capacidad para el deporte y la aventura natural., con proyectos que propician efectos multiplicadores, entre otros el poder de atraer y retener a los jóvenes.

El ciclismo es una práctica deportiva popular. Millones de personas utilizan la bicicleta como vehículo eficaz para su movilidad, transporte, ocio y deporte en todo el mundo.

El Giro, el Tour, la Vuelta son argumentos para fijar en la memoria colectiva de una comunidad el aprecio por su territorio, su exhibición orgullosa y su pretensión de ser identificado por los otros como país de calidad.

La reiteración es consustancial a las vueltas, la diferencia la ponen los lugares que singlan, entrevistos como paisajes y, entre todos, son las montañas las que aportan el mito, el símbolo, constituyendo el escenario para dramatizar un espectáculo que atrae a millones de espectadores en el mundo, algunos de los cuales fabrican en China las bicicletas que utilizan para escalar las montañas europeas, que los atraen como lugares de peregrinación ciclista.

Existen comisiones parlamentarias en las Cortes españolas para estudiar la práctica del ciclismo y proponer medidas para mejorar su ejercicio en condiciones de seguridad, pero no se trata del enfoque integral que vemos reflejado en otros parlamentos, como es el caso del Reino Unido, donde una comisión de comunes y lores ha realizado un informe con recomendaciones sobre las condiciones del ciclismo en el Reino Unido (APPCG, 2012). Este esfuerzo concertado para elevar al ciclismo a política de Estado está dando allí sus frutos en diversos niveles. Por ejemplo Grous (2012) evalúa lo que llama «economía del ciclismo», cuya aportación a la nacional la estima en «2,9 billones de libras esterlinas por año con una perspectiva de crecimiento fuerte y sostenido a largo término». Sería interesante estudiar medidas de desarrollo de proyectos vinculados al ciclismo y a los deportes de aventura en la montaña.

\section{Cuidar la alimentación y La gastronomía}

La montaña es territorio de producción agraria; hoy sus limitaciones pueden ser sus ventajas. Planteamos como medida a considerar la de vincular la montaña al concepto de alta calidad alimentaria, que puede ser usado como aglutinante de otros tres: producir mejor, transformar mejor, consumir mejor. Concepto manejado en clave de desarrollo territorial para facilitar externalidades; integrar a productores y empresas locales en cadenas de valor que extiendan el concepto de seguridad alimentaria, como amplificador de las capacidades de la montaña para proteger al país del riesgo previsible en materia alimentaria, ante un futuro de incertidumbre en un horizonte temporal de veinte años. La certificación de alta calidad alimentaria sería la expresión del compromiso por la excelencia adquirido por los participantes en la cadena de valor y que se visualizaría in situ mediante eventos de proyección internacional. Esto contribuirá también a la reforma de la actividad turística, al incluirla en la cadena de valor mediante acciones relacionadas con el paisaje, como producto social que hoy debe integrar la evolución de los ecosistemas, más allá de la perspectiva estética o contemplativa, contribuyendo al mantenimiento de la biodiversidad, al dar salida, en forma de productos, a sus componentes, que así contribuyen a la ocupación dinámica de las montañas.

\section{CONCLUSIONES}

Es difícil precisar los límites de las montañas, pues no hay consenso sobre los criterios a utilizar. Sólo dos están libres de discusión, la altitud y la pendiente. A partir de ellos y en una sucesiva concatenación causal se pueden derivar otros, que en unos casos actúan como determinantes, es la extensión superficial, y en otros como determinados, es la gradación bioclimática. Los dos básicos provocan la acción de la fuerza de la gravedad, que tiende a sacar fuera de los límites montanos a sus variados recursos; por eso, la montaña actúa como reserva energética para el ciclo geográfico general y es proveedora de recursos energéticos para las partes más bajas. Asuntos de carácter estratégico para la vida.

La tendencia exportadora es inherente a las montañas, por ello el hombre se esforzó por crear unos sistemas territoriales que garantizasen un cierto control sobre el proceso y aprovechasen los potenciales que genera la presencia de pisos ecológicos, determinados por el sistema de interacciones entre altitud, ciclo solar y acción humana. Tales sistemas son complejos geográficos frágiles, por vulnerables, y que utilizaban la tecnología conocida en cada fase del ciclo histórico, caracterizados, hasta ahora, por su dinámica lenta que hacía que los sistemas pudieran asimilar los cambios que tendían a perturbarlos. 
Como sistemas territoriales la familia de los de montaña parte de su identidad física que se matiza con otros atributos, como la inclusión en ejes de desarrollo motores o en integración, o su asentamiento dominante, ya sea metropolitano, urbano, rural o natural. Ello da una heterogeneidad de montañas, pues hay diferentes tipos, pero en todos ellos está presente la diversidad, tanto en los ámbitos urbanos o en los rurales.

La montaña también induce al enclavamiento, por su carácter rugoso y las dificultades para las comunicaciones, inherentes al mismo, pero en el estadio actual de civilización el enclavamiento puede dejar de ser consustancial a la identidad montana; aunque a éste lo sustituyen ahora otros determinantes, como la polarización territorial, que induce descohesión regional al situar a buena parte de las montañas en líneas tendenciales divergentes con otros territorios, cuyas dinámicas son opuestas y muy contrastadas, siendo la fuerza de la tendencia demográfica un problema para la mayor parte de las montañas debido a su carácter perturbador, que lleva a la disolución de sus sistemas territoriales por el envejecimiento; originándose así un proceso de recomposición territorial que hace aparecer dentro de las montañas sistemas territoriales nuevos y a otros los lleva hacia el vacío y la pérdida de sus valores ciudadanos, pues pasan a ser espacios naturales.

La problemática de las montañas es importante para muchos Estados, por su dimensión superficial, y para muchas regiones es decisiva, por ser todas ellas montañosas; por ello, no se debe identificar a la montaña con lo agrario ni con lo rural, pues su impronta física marca a todo el territorio, que necesita modelos de ordenación capaces de encajar armónicamente su funcionalidad dentro de su carácter singular.

La circunstancia que había acogido al modelo funcional agrario tradicional en España alcanza optimizada la década de 1980 y se disuelve rápidamente durante ella, sin crujidos, adormecida por una política asistencial dirigida a las explotaciones agrarias, que se van agotando, sin que ahíje un sistema funcional y territorial alternativo, quizás porque se veía a la montaña como un reducto de tradición disfuncional, lo que acelera su despoblamiento. Hoy el gran juego global deja algunas bazas a los territorios de montaña, manejados por una escasa población cuyas perspectivas demográficas constituyen el problema, y cuyo modelo demográfico en una regiónparadigma, queda dibujado en este artículo para poder en evidencia el envejecimiento y la dependencia, pero también la existencia de plataformas de vida y actividad, las villas, desde las cuales puede operarse la recomposición del territorio, para poner bajo control un problema grave de cohesión territorial, que necesita sumar otras políticas a las asistenciales de carácter agrario, claramente insuficientes para el objetivo de mantener ocupada dinámicamente la montaña.

Se propone un método de gobernanza territorial basado en la lógica del proyecto; y un modelo de actividad basado en la economía de la identidad, pues se estima que en los territorios de montaña existen capacidades que pueden ser puestas en juego al ser atractivas para otros territorios. Para ellos se apunta un decálogo de medidas. Unas de carácter transversal y procedimental, relativas a una nueva gestión territorial mediante la lógica de proyecto, con la que conducir procesos de desarrollo basados en el enfoque de las capacidades para las unidades territoriales; en cuyo concurso se puedan incorporar jóvenes procedentes de las universidades, formados en una nueva disciplina, que acompañen el proceso, creando con su presencia un fondo vital y plataformas de incorporación del conocimiento y adición de elementos de valor. Se trata de la participación institucional de las universidades en uso de su tercera función: la cooperación al desarrollo territorial. Se forjaría así un compromiso por las montañas, que el Estado debe garantizar eficazmente pues la nación las necesita ocupadas y activas; pues son proveedoras de valiosos recursos para la vida. La provisión de estos recursos de alto valor territorial, no puede hacerse prescindiendo de su determinación geográfica, por lo que se necesita identificar y considerar las unidades específicas de ordenación del territorio montañés e integrar su recomposición en sucesivas escalas. Su operación se despliega desde las bases del poblamiento, las villas. Por debajo, las aldeas se integran como núcleos de las células de gestión territorial, proponiéndose para ellas su catalogación. La protección de la voz de las comunidades; el impulso a la cooperación y coordinación en marcos territoriales amplios, fomentará la creación en las regiones transfronterizas de nuevas centralidades complementarias a las metropolitanas, mediante modelos multifuncionales de actividad que amplifiquen tendencias generales de la sociedad, como los deportes y las actividades de aventura en la naturaleza y, en concreto, el ciclismo, como práctica, economía, espectáculo y pedagogía social sobre las montañas y su paisaje. Finalmente, se reclama la puesta en valor de la Alta Calidad Alimentaria de las producciones agrarias de la montaña como una cautela necesaria ante un riego previsible y como formación de una cadena de valor para productos de excelencia. 


\section{BIBLIOGRAFÍA}

Agenda Territorial Europea (ATE) 2020 (2011): Hacia una Europa integrada, inteligente y sostenible de regiones diversas. Aprobada en el Consejo informal de Ministros de Ordenación del Territorio y Desarrollo Territorial celebrada el 19 de mayo de 2011, en Gödölló (Hungría).

Aguiar, C., O. Rodrigues, J. Azevedo y T. Domingos (2009): «Montanha», en H. E. Pereira, T. Domingos, L. Vicente y V. Proença: Ecossistemas e bem-estar humano. Avaliaçao para Portugal do Millenium Ecosytem Assessment. Escolar Editora, Lisboa, pp. 295-339.

All Party Parliamentary Cycling Group (2012): Get Britain Cycling. APPCG Inquiry.

ATECMA: Fundamentos para la definición de Zona de Montaña en España y estudio de la aplicación de la indemnización compensatoria en zonas de montaña. Inédito, D. G. de Biodiversidad, Ministerio de Medio Ambiente, Madrid.

Anglada, S., E. Balcells, J. Creus-Novau, J. M. García Ruiz, C. E. Martí Bono y J. Puigdefàbregas (1980): La vida rural en la montaña española. Orientaciones para su promoción. Monografía 107, Instituto de Estudios Pirenaicos, Jaca.

Balcells Rocamora, E. (1978): «La montaña como reserva». Estudios Geográficos, núm. 153, pp. 443-472.

CPRM/AAC (2005): Atlantic Spatial Development Perspective. Santa María da Feira (Portugal).

Cortés Macías, R. (1995): «La PAC y las zonas desfavorecidas en la UE. Resultados de la indemnización compensatoria». Baetica, núm. 17, pp. 53-65.

Daumax, M. (1976): La vie rurale dans le Haut Aragon oriental. Instituto de Estudios Oscenses y de Geografía Aplicada/Csic.

Delgado Viñas, C., y J. I. Plaza Gutiérrez (2012): Territorio y paisaje en las montañas españolas. Estructuras y dimensiones espaciales. Estudio, Santander.

Diamond, J. (2013): El mundo hasta ayer. ¿Qué podemos aprender de las sociedades tradicionales? Debate, Barcelona.

ENRD (EUROPEAN NETWORK FOR RURAL DEVELOPMENT) (2013): Breve guía sobre las propuestas de la CE relativas al desarrollo rural en la UE después de 2013.

FernándeZ ARroyo, R. (coord.) (2003): Orientaciones para la gestión, conservación y desarrollo sostenible de las zonas de montaña en España. Ministerio de Medio Ambiente, Madrid.

Fillat, F., J. Aguirre, F. Paune y C. Fondevilla (2009): «La conservación de la montaña alpina española y el bienestar humano».Revista Ambient@,núm.98 (Ecosistemas).

Galdós Urrutia, R., y E. Ruiz UrRestarazu (2008): «La diversidad de la montaña vasca. Ensayo de tipologías para políticas territoriales». BAGE, núm. 47, pp. 31-48.

García Ruiz, J. M. (2006): «El profesor Enrique Balcells Rocamora». Cuadernos de Investigación Geográfica, núm. 32, pp. 161-166.

Gobierno del Principado de Asturias: pDR (Feader) 2014-2020

Gómez Limón, J. A., I. Atance Muñiz y M. Rico GonZÁLEZ (2007): «Percepción pública del problema del despoblamiento del medio rural en Castilla y León». Ager, núm. 6, pp. 9-60.

Grous, A. (2012): The British Cycling economy. Gross cycling product report. LSE.

Lacosta Aragǘés, A. J. (2001): «Aproximación al sector del turismo activa y de aventura en España. Implicaciones territoriales y distribución espacial», en Forma y función del territorio en el nuevo siglo. Actas del XVII Congreso de Geógrafos Españoles. AGE/ Universidad de Oviedo, pp. 358-364.

MEA (Millennium Ecosystem Assessment) (2005): Strengthening Capacity to Manage Ecosystems Sustainably for Human Well-Being. Final Draft.

Pérez Díaz, V. (2010): Universidad, ciudadanos y nómadas. Nobel, Oviedo.

Red Rural Nacional (2011): Carta Española de las Montañas, borrador 2005, y Carta de las montañas españolas, texto aprobado por el Grupo de Trabajo de la Red Rural Nacional, 2011

RegioLab (2014): Primer informe de diagnóstico de la situación y perspectivas demográficas del Principado de Asturias. Gobierno del Principado de Asturias.

Rodríguez GutiérRez, F. (1987): «La diversidad de la montaña legal asturiana. Bases para el desarrollo de una política asturiana de montaña». Ería, núm. 14, pp. 195-211.

- (1989): «La rentabilidad de las explotaciones ganaderas semiextensívas en la Montaña Central de Asturias». Ería, núm. 18, pp. 27-34

- (1993): «El balance de un decenio de política de montaña en España». Ería, núm. 30, pp. 61-72.

- (2001): «El género de vida y el paisaje de los vaqueros de Asturias», en Paisajes y paisanajes. Organización del espacio y vida cotidiana tradicional. Trea, Gijón, pp. 13-26.

- (2004): «El enfoque de las capacidades para la gobernabilidad del territorio». Ería, núm. 63, pp. 105117. 
- y R. ViLleneuve (2001): «El papel de las universidades en la activación de procesos de desarrollo territorial». Ería, núm. 56, pp. 294-299.

ROMERo, J., y J. FARINós (eds.) (2006): Gobernanza territorial en España. Universitat de Vàlencia.

SADEI (2013): Reseña estadística de los municipios asturianos.

Salais, R., y R. Villeneuve (eds.) (2004): Europe and the Politics of Capabilities. Cambridge University Press.

Villeneuve, R., y F. Rodríguez GutiérRez (dirs.) (2002): Contribución de los interlocutores sociales nacionales al proceso de Luxemburgo (Coparsoc). Comisión Europea VS/2001/0750. Inédito.

\section{FUENTES}

Boletín de las Comunidades Europeas: El futuro del mundo rural. Сом (88) 501, 28/07/1988, suplemento 4/88, disponible en <www.aei.pitt.ed>.

Comisión Especial para el Estudio de Medidas que Eviten el Despoblamiento de las Áreas de Montaña, 2013-2014, disponible en <www.senado.es>.

Datos básicos de Asturias 2013, disponible en <www. sadei.es $>$.

Directiva 86/466/CEE relativa a la lista de zonas comunitarias desfavorecidas. DOUE de 24 de septiembre de 1986.

Directiva 91/465/CEE por la que se modifica la directiva 86/466/CEE relativa a la lista de zonas agrícolas desfavorecidas. DOUE de 7 de septiembre de 1991.

Decisión de la Comisión 89/566/CEE por el que se modifi- can los límites de las zonas desfavorecidas en España. DOUE de 25 de octubre de 1989.

European Network for Rural Development. Breve guía sobre las propuestas de la $C E$ relativas al desarrollo rural en la UE después de 2013, disponible en <www.enrd.org>.

Ley 25/1982, de Agricultura de Montaña. BOE de 10 de julio de 1982 .

Ley 2/1983 de Alta Montaña. DoGC/312, de 16 de marzo de 1983.

Ley del Patrimonio Natural y de la Biodiversidad. BOE de 13 de diciembre de 2007.

Ley 45/2007 para el Desarrollo Sostenible del Medio Rural. $B O E$ de 14 de diciembre de 2007.

Orden de 6 de marzo de 1985, por la que se establece la primera delimitación perimetral de la superficie susceptible de ser declarada zona de agricultura de montaña. BOE de 6 de marzo de 1985.

Orden de 9 de junio de 1986 por la que se establece la segunda delimitación perimetral de la superficie susceptible de ser declarada zona de agricultura de montaña. BOE de 13 de junio de 1986.

Orden de 21 de julio de 1987 por la que se establece la tercera delimitación perimetral de la superficie susceptible de ser declarada zona de agricultura de montaña. BOE de 21 de julio de 1987.

Programas regionales 2014-2020, disponible en <www. magrama.gob.es>.

Reglamento UE-1305/2013 del Parlamento Europeo y del Consejo de 17/12/2013 relativo a las ayudas al desarrollo rural a través del Feader. DOUE de 20 de diciembre de 2013.

<www.millenniumassessment.org/es>. 